\title{
History
}

\section{Department of Plastic Surgery, IPGME\&R, Kolkata}

\author{
S. S. Chatterjee \\ Associate Professor, Department of Plastic Surgery, IPGME\&R, Kolkata, India.
}

Address for correspondence: C/O Mr. P. Chatterjee, 84 SA/1B, Block-E, New Alipore, Kolkata - 700053 , India. E-mail: ssc@onlysmart.com

\section{INTRODUCTION}

t was extremely pleasing to learn of the decision of our editor, Dr. Mukund Thatte to delve into the history of Plastic Surgery units in India. Unless we do so, we can never really go ahead. "Those who forget history are condemned to repeat it". But having gone through the article of Dr. Kale and also having heard his lecture in one of the recent conferences, I am now somewhat hesitant to claim that ours was the first civilian Department of Plastic Surgery in India. However, a military unit had been opened earlier. The records say that Professor Murari Mohan Mukherjee was the Head of the Department of Plastic Surgery, IPGME\&R and SSKM hospital (formerly Presidency General hospital - P.G) from 1956 to 1965. He had already started Plastic Surgical operations since 1952 as Residential Medical Officer in the Department of General Surgery. By 1955, he did enough to draw the attention of the then Chief Minister of West Bengal, Late Dr. B. C. Roy. Indeed the inauguration of the Department in 1956 was done at the hands of our late Prime Minister Pandit Nehru in the presence of late Dr. B. C. Roy, the then Chief Minister of West Bengal. Dr. B. C. Roy had brought Mr. B. K. Rank, a renowned hand surgeon from Australia in those days prior to inauguration of the department to train future Plastic Surgeons. I still remember, Dr. Samir Banerjee, a close associate and a student of late Professor Mukherjee mentioned this in his M. M. Mukherjee oration in the annual meeting in Ahemdabad (Mehsana APSICON) in 2001.
Discussion on the first unit cannot be held without alluding to Professor M. M. Mukherjee's contributions. Having returned from UK in November 1951 where he was closely associated with Mr. Kilner, he began his journey in Plastic Surgery in India. There was no problem in this new discipline he did not touch. Repair of cleft lip and palate, skin cover for various ulcers, reconstruction after cancer surgery, hand injuries, rhinoplasty for depressed nose, dermabrasion for pock marks, blepharoptosis, lymphedema, hypo and epispadias, multistaged flap operations and management of burn patients were part of his routine. In short everything possible within limits of contemporary knowledge. He was also busy in administrative work, social work and a roaring private practice. The Government had specially permitted him to practice despite attachment to a teaching institution. Perhaps due to this, academics had suffered a little. It was not until 1979 , that the $\mathrm{M}$. Ch. course was started in the University of Calcutta. Not a thing to be proud of when a Department had already been established 23 years ago.

During his tenure, research work was done on following subjects:

- Keloids and hypertrophic scars

- Chronic lymphedema of lower limbs

- Chronic venous insufficiency

- Cheek flap in cleft palate

- Velopharyngeal closure studies in Cleft palate patients 
- Reconstruction of claw hands in leprosy

- Maxillary deficiency in cleft patients

- Alveolar bone grafts in cleft patients

- Sensory functional return following different types of reconstruction in hand injuries

- Immunological aspects of burns

- Homografts in burns

- Evaluation of different methods of treatment of ectopia vesicae

Papers presented by Prof. Mukherjee at International conferences:

- Severe injuries of forearm and hand - International Conference of Plastic Surgeons, London, 1959

- Treatment of recurrent parotitis by a newly devised operation (relocation of the duct) - All Asia Pacific

Surgeons' Conference in Japan, 1963

- Analysis of causes of death in severe burns International conference of Burns Research in Edinburgh, 1965

- Lymphedema, Elephantiasis of the leg and its treatment by a lymphatic bridge flap - 4th International Congress of Plastic and Reconstructive Surgery, Rome, 1967

- Cheek flap for short palate - International Congress on Cleft Palate, USA, 1969

- Reconstruction of Penis - The Asian Pacific Congress of Plastic surgery, New Delhi, Jan., 1973.

His academic contributions were recognized in Millard's Cleft Craft, Part-III and Clinics in Plastic Surgery, January 1974. Superiorly based pharyngeal flap was his great favourite in cleft palates. Mention must be also be made of four of his junior colleagues Dr. Debmalya Banerjee, Dr. Samir Banerjee, Dr. Sankar Sen and Dr. Bankim Chandra without whose sacrifice and hard work, perhaps Professor Mukherjee would not be as famous as he was. Dr. Debmalya Banerjee was also the coauthor of 'Filarial Elephantiasis of the Leg' in Clinics in Plastic Surgery, January 1974. Dr. Bankim Chandra was the first M. Ch. (in Plastic Surgery) of the University of Calcutta in 1981.

Subsequently Professor Amit Ganguly continued and popularized the cheek flap and tongue flap in palate and oral surgery respectively. His name is also referred to in Cleft Craft and McCarthy's textbook of Plastic Surgery. Incidentally as I heard, it was on one occasion of closure following ablative surgery of an oral cancer that Professor Mukherjee commented "don't you think the tongue is quite a big one in this lady. Why not use it for closure of the defect?" That started off a flurry of use of tongue flap in various intraoral operations.

Since 1965 to the present day, headship passed via Professors Anjali Mukherjee, Meera Sen, Siti Roy Chowdhury, Chhanda Banerjee, and P.K. Sinha to the present head Professor B. K. Majumdar. In 1975, a twenty five bedded Burns Research unit was started. While everyone had contributed to the development of the Department in their own capacities, contribution of Dr. Siti Roy Chowdhury needs special mention. She had modernized the Department. She was responsible for introducing operating microscope, power saw and drill, establishing a modern operation theatre and an entire ward exclusively for Plastic Surgery. The strength stood at 80 in Plastic Surgery wards and 25 exclusively in the Burns Research Unit. At any point of time with extra patients admitted the load stood on an average around 110-115. Perhaps the second highest in the country after Safdarjung Hospital in New Delhi.

In late seventies and early eighties, Professor Sankar Sarkar who had returned after training in UK and USA and gave us some exposure to newer ideas and operations. The author was a student of MS (General Surgery) in the Institute then and remembers Dr. Sarkar's popularity in the Institute among young surgeons and PG trainees, solving many complicated problems by newer flaps.

Further contributions came during the tenure of Professor Chhanda Banerjee who regularized the academic programme. Professor P. K. Sinha devoted one day in the week exclusively for micro vascular surgery and training of students in the anatomy dissection hall. The present Head of the Department Prof. B. K. Majumdar has also contributed in a number of ways to uplift the Department. He has been doing this even before he became the Head of the 
Department. He developed a beautiful and cosy seminar room with audiovisual teaching facilities. He is/was responsible for holding regular workshops consisting of both national and international faculties. He has already replaced the previous practice of holding back the $\mathrm{M}$. Ch. trainees in any particular unit for a period of time. They are utilized anywhere the department needs them or wherever they need the training. The entire routine of their 3 years training is already handed over to them at the beginning of their course. He has also recently ensured availability of operation theatre for emergency hand and micro vascular surgery. He as the secretary of the Association of Plastic Surgeons of West Bengal has started traveling fellowships for members (particularly for trainees) and last but not the least the duty room of the Medical Officers, House staffs and trainees has been upgraded with comforts of a refrigerator, TV with cable connection, a water purifier and 3 beds.

Currently, the Department can boast of having exposed its trainees to even hair transplant and liposuction (courtesy Dr. Manoj Khanna's voluntary service). Other cosmetic surgery procedures breast reduction and rhinoplasty are by no means rare. Recently even Craniofacial surgery has been started with the help of Neurosurgical colleagues. I do not know of any Government Institution where exposure to all subspecialties of Plastic Surgery are given.
However, I must conclude with a note of dissatisfaction with regard to regular publications and presentations at the national forum from this Institute. Though Professors Siti Roy Chowdhury and Chhanda Banerjee have a number of publications to their credit, palpable presence of APSI members from this institute at various conferences is lacking for various reasons. The author feels this may be due to:

- Thesis not being compulsory for M.Ch. trainees

- Doctors here are more private practice oriented

- Doctors do not want (?)/have teamwork

- A peculiar psyche of non documentation of work

- No financial support of the Government for research work

- $\quad$ For a long time the Government has paid no attention to modernisation

Finally, I add a note of hope with conviction. "The scenario is changing". You will soon see.

\section{ACKNOWLEDGEMENTS}

I am indebted to:

Professor Debmalya Banerjee for information on history of IPGME\&R and Professor Murari Mohan Mukherjee in particular Professor Gurudas Mukherjee for kindly supplying priceless photographs and information 